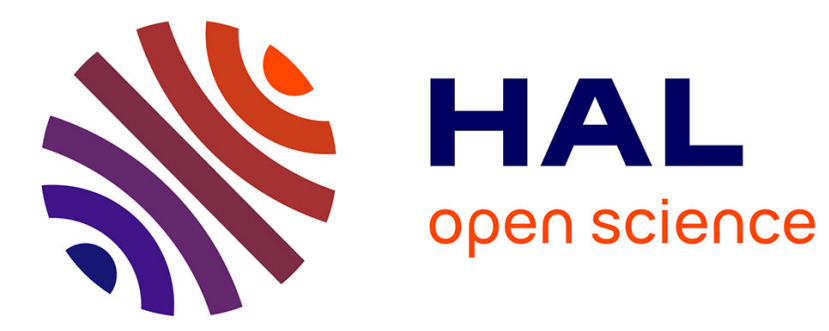

\title{
Quantum wires obtained by dislocation slipping
}

F. Voillot, Robert Carles, Michel Goiran, C. Guasch, J. Peyrade, Eléna

Bedel-Pereira

\section{To cite this version:}

F. Voillot, Robert Carles, Michel Goiran, C. Guasch, J. Peyrade, et al.. Quantum wires obtained by dislocation slipping. Journal de Physique IV Proceedings, 1993, 03 (C5), pp.C5-339-C5-342. 10.1051/jp4:1993570 . jpa-00251657

\section{HAL Id: jpa-00251657 https://hal.science/jpa-00251657}

Submitted on 1 Jan 1993

HAL is a multi-disciplinary open access archive for the deposit and dissemination of scientific research documents, whether they are published or not. The documents may come from teaching and research institutions in France or abroad, or from public or private research centers.
L'archive ouverte pluridisciplinaire HAL, est destinée au dépôt et à la diffusion de documents scientifiques de niveau recherche, publiés ou non, émanant des établissements d'enseignement et de recherche français ou étrangers, des laboratoires publics ou privés. 


\title{
Quantum wires obtained by dislocation slipping
}

\author{
F. VOILLOT, R. CARLES, M. GOIRAN, C. GUASCH, J.P. PEYRADE and E. BEDEL*
}

Laboratoire de Physique des Solides, LA074, INSAT, 31077 Toulouse cedex, France

* LAAS du CNRS, 7 av. du Colonel Roche, 31077 Toulouse cedex, France

\begin{abstract}
Dislocation slipping is used as an atomic scale tool to cut a $5 \mathrm{~nm} \mathrm{GaAs}$ single quantum well (QW) grown by MBE on a (001) GaAs substrate into quantum wires (QWW). Three point deformation bending is used to control dislocation slipping. The minimum value of the QWW widths is evaluated to $25 \mathrm{~nm}$. PL studies after deformation show intense peak, shifted in regard to the undeformed SQW in good agreement with theory. Raman scattering results confirm the additional lateral confinement.
\end{abstract}

\section{INTRODUCTION}

QWW have received intense interest over the past few years but for experimental studies the most important step is the fabrication and control of nanostructured semiconductors. Two major ways can be distinguished : the direct growth of wires (on vicinal or V-grooved substrates) [1] and the patterning of existing two dimensionnal (2D) structures by nanometer scale lithography followed by etching [2] or by selective ion implantation [3] but these techniques have to deal with either surface recombination or smooth potential barriers; in both cases the size dispertion is small but a lot of active material is lost during the processes.

Recently, we showed that dislocation could be an ideal tool to cut an existing 2D structure in ID or even $\mathrm{OD}$. The method we propose leaves the entire active region free of damage and thus keeps the optical and transport properties of the system unaltered except for the consequences of the lateral confinement; it is also applicable to any crystalline material but we tested it on the well known $\mathrm{GaAs} / \mathrm{Al}_{\mathbf{x}} \mathrm{Ga}_{1-\mathrm{x}}$ As system.

\section{PRINCIPLE}

The basic principle can be simply described as follow : a GaAs crystal, submitted to a stress higher than its elastic limit, deforms plastically if the temperature is sufficient to allow motion of the dislocations in their slip planes. A source emits a dislocation loop which increases in size until it reaches the free 
surface of the crystal : at this point, one part of the crystal is shifted with respect to the other by an amount equal to the Burgers vector $\vec{b}$ of the dislocation.

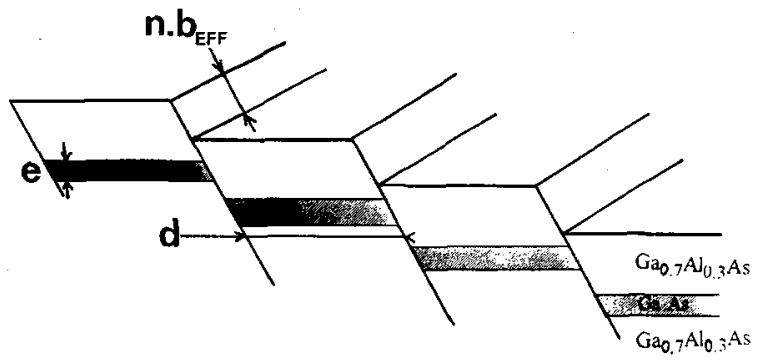

figure 1 : schematic view : different sources have been considered to obtain QWW.
It should be pointed out that, in the volume, the crystalline perfection is fully restored. So, if a GaAs layer of thickness $e$ is sandwitched between two AlGaAs barriers it will be completly cut when a source has emitted $\mathrm{n}$ dislocation loops with $\mathrm{n}$ satisfying $n \cdot b_{\text {eff }} \geq e$, where $b_{\text {eff }}$ is the component of the Burgers vector along the growth direction

So, the control of the slip by choosing the crystal orientation, stress conditions, temperature and sources density, will provide a perfectly adapted tool to pattern a 2D stucture in 1D (or even OD).

\section{DEFORMATION CONDITIONS}

GaAs plasticity in simple slip configuration has been widely used [4], but since M.B.E. grown $\mathrm{AlGaAs} / \mathrm{GaAs}$ systems are available only on (001) substrates, we choose to use a three point bending test in order to demonstrate the efficiency of the method for the following reasons : a bending test is a simple way to apply a tensile stress, no cutting stress being involved; in addition, from the (001) surface to the $(00 \overline{1})$ one, the stress varies linearly from tension to compression and the neutral plane at the center acts as a barrier for dislocation slipping; and finally we can obtain in only one sample different deformation conditions with a curvature radius varying from $3 \mathrm{~mm}$ to infinity. The major disadvantage of being bended for our samples lies in the fact that this configuration causes a major problem for photoluminescence (PL) measurements and most important, polarisation studies. But it should be emphasized that other configurations can be used on different substates.

The stress orientation along [1 $1 \overline{1} 0]$ favours the development of $60^{\circ} \alpha$ dislocations sources from the surface on which the active layer is grown. The choosen temperature $673 \mathrm{~K}$ is much lower than the growth temperature to prevent any degradation of the sample. The surface strain rate is about $10^{-5} \mathrm{~s}^{-1}$ in order to favour slipping deformation mechanisms.

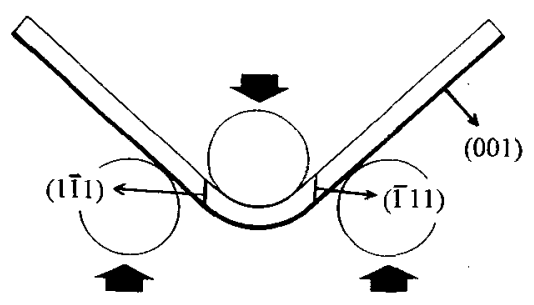

figure 2 :three point bending test

\section{RAMAN AND PL MEASUREMENTS}

Raman and PL spectra are recorded at room and liquid nitrogen temperatures using several $\mathrm{Ar}^{+}$laser lines as excitation. The laser beam is focussed on the most deformed part of the sample. The signal is dispersed trough a triple spectrometer and collected by a low noise photo-counting system. Three samples grown by M.B.E. on (001) GaAs Substrates are analysed within the same experimental conditions: an homoepitaxial GaAs layer (A), a $5 \mathrm{~nm} \mathrm{QW}$ embedded in $\mathrm{Al}_{\mathrm{X}} \mathrm{Ga}_{1-\mathrm{X}} \mathrm{As}$ before (B) and after(C) deformation. In order to enhance the $Q W$ signal versus the substrate one the thickness of the top barrier is limited to $20 \mathrm{~nm}$ whereas that of the bottom barrier (between the QW and the substrate) is 
fixed at $200 \mathrm{~nm}$. Taking into account the value of the absorption coefficient of GaAs, $\alpha_{1}=(46 \mathrm{~nm})^{-1}$ and of $\mathrm{Al}_{0.36} \mathrm{Ga}_{0.64} \mathrm{As}, \alpha_{2}=(81 \mathrm{~nm})^{-1}$ for $\lambda=454.5 \mathrm{~nm}, 97 \%$ of the $\mathrm{GaAs}$ signal originate from the $\mathrm{QW}$. As a matter of fact no substrate luminescence is detected, so only barriers and QW are analysed.

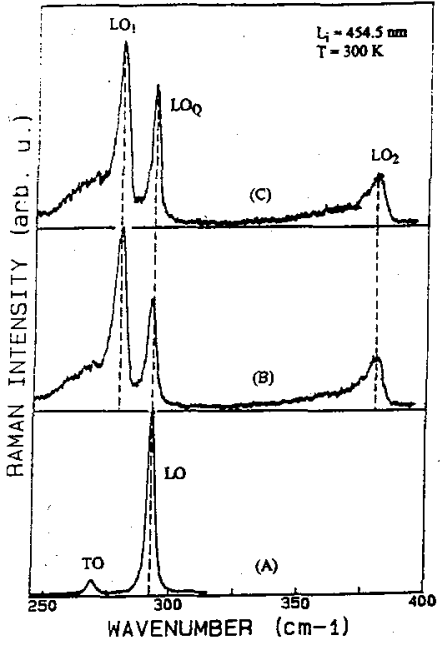

figure 3 : Raman spectra
Three structrures are easily identified on Raman spectra recorded at $300 \mathrm{~K}$ : the GaAs-like $\left(\mathrm{LO}_{1}\right)$ and AlAs-like $\left(\mathrm{LO}_{2}\right)$ modes of the barriers and confined mode of the $\mathrm{QW}$ $\left(\mathrm{LO}_{\mathrm{Q}}\right)$. The frequency separation $\left(110 \mathrm{~cm}^{-1}\right)$ between $\mathrm{LO}_{2}$ and $\mathrm{LO}_{1}$ allows to determine the composition [5]: $\mathrm{x}=0.36 \pm$ 0.01 . The frequency shift on spectrum $B\left(-1 \mathrm{~cm}^{-1}\right)$ of the $L O_{Q}$ versus bulk GaAs $L O$ manifests itself as a $2 \mathrm{D}$ confinement effect [6].The comparison between $B$ and $C$ spectra shows negligible modification of the barrier. Deformation leads to a small braodening, an intensity increase and a shift towards higher frequency of the $\mathrm{LO}_{\mathrm{Q}}$ feature. Neither chemical intermixing nor structural degradation is observed. On the contrary, the increase of the $\mathrm{LO}_{\mathrm{Q}}$ signal shows a selective enhancement of the electronLO phonon interaction. This may originate in and additive lateral confinement. Polarisation measurements (not reported here) show that the in-plane isotropy of the GaAs layer is effectively lost: the $\mathrm{LO}_{\mathrm{Q}}$ signal is only modified for incident and scattered field polarisation parallel to the expected wire direction.

The PL spectra from the QW and from the barrier are recorded at $77 \mathrm{~K}$ using the highly absorbed $454.5 \mathrm{~nm}$ line.

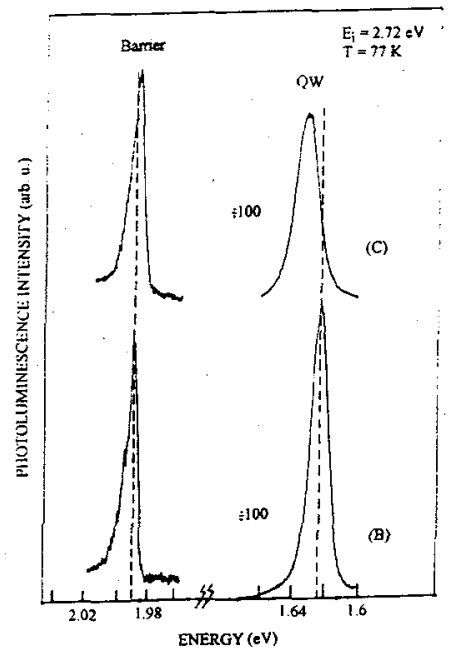

figure 4 : PL spectra
The energy position of the peaks $(1.623$ and $1.989 \mathrm{eV})$ in the undeformed sample (B) is in good agreement with the alloy composition and QW width. After deformation (C) no lineshape change is observed on the signal assigned to the barriers, testifying that their chemical and structural characteristics are preserved during the deformation process. Only a sligth energy red-shift $(-2.5 \mathrm{meV})$ is detected. It may originate from (a) a tensile residual stress, (b) a lowering of the $\mathrm{x}$ composition and/or (c) a local heating by the exciting beam. However deformation leads to a blue shift $(+9.3 \mathrm{meV})$ of the QW PL signal. It should be pointed out that the PL signal intensity is only sligthly reduced. Hence, the energy shift is of opposite sign for the QW and the barriers: the (a) and (c) hypothesis can be ruled out. Moreover, the constant value of the $\mathrm{LO}_{2}-\mathrm{LO}_{1}$ Raman frequency and the positive shift of the $\mathrm{LO}_{\mathrm{Q}}$ frequency are already in contradiction with hypothesis (b). Therefore, only the effect of and additional confinement is relevant. 
In addition, the exciton energy shift value $(10 \mathrm{meV})$ is in good agrement with an average wire width of $25 \mathrm{~nm}$ [7]. The broadening of the line observed on the deformed sample can be reasonably attributed to fluctuations on the wire width.

\section{CONCLUSION}

The dislocation is used here as an interatomic tool which does not degrade the $2 \mathrm{D}$ crystalline structure. The results reported here, either Raman spectroscopy or PL, give evidence that additional lateral confinement is obtained in a controlled deformation process. This method presents the advantage of producing wires on the whole MBE grown surface and is particularly well suited for GaAs/AlGaAs systems were mechanical properties of both compounds are very close. In addition, due to its principle, the obtained wires have the same length (as large as few $\mathrm{mm}$ ) as the starting sample itself.

[1] - Tsuchiya M., Gaines J.M., Yan R.H., Simes R.J., Holtz P.O., Coldren L.A. and Petroff P.M., Phys. Rev . Lett. 62 (1989) 466.

- Kapon E., Hwang D.M. and Bhat R., Phys. Rev. Lett 63 (1989), 430.

[2] Izraël A., Marzin J.Y., Sermage B., Birotheau L., Robein D., Azoulay R., Benchimol J.L., Henry L., Thierry-Mieg V., Ladan F.R. and Taylor L., Jap. J. Appl. Phys. 30 (11B) (1991), 3256.

[3] Vieu C., Schneider M., Benassayag G., Planel R., Birotheau L., Marzin J.Y. and Descouts B., J. Appl. Phys. 71 (10) (1992), 5012.

[4] Boivin P., "Plasticité de GaAs en fonction du dopage électronique", Thesis Université de Poitiers, 1988.

[5] Saint-Cricq N., Landa G., Renucci J.B., Hardy I. and Muñoz-Yague A., J. Appl. Phys. 61 (1987), 1206.

[6] Arora A.K., Suh E.K., Ramdas A.K., Chambers F.A. and Moretti A.L., Phys. Rev. B 36 (1987), 6142.

[7] Bockelmann U. and Bastard G., Phys Rev B 45 (1992), 1688. 